${ }^{1}$ Addiction Research Foundation, Cannabis. Toronto, Addiction Research Foundation, 1970

2 International Medical Digest, 1937, 31, 183.

3 Ludlow, P., Saturday Night, 1965, 80, 28.

4 Manno, J. E., Kiplinger, G. F., Haine, S. E., Bennett, I. F., and Forney, R. B., Clinical Pharmacology and Therapeutics, 1970, 11, 808.

5 Weil, A. T., and Zinberg, N. E., Nature, 1969, 222, 434.

- Crancer, A., Dille, J. M., Delay, J. C., Wallace, J. E., and Haykin, M. D., Science, 1969, 164, 851.

7 New York. Mayor's Committee on Marihuana. The Marihuana Problem in the City of New York, ed. G. B. Wallace and E. V. Cunningham.

Lancaster, Pa., Cattell, 1944.
Weil, A. T., Zinberg, N. E., and Nelsen, J. M., Science, 1968, 162, 1234.

- Weil, A. T., Zinberg, N. E., and Nelsen, J. M., Science, 1968,

10 Goode, E. J., Fournal of Health and Social Behaviour, 1969, 10, 83.

Downes, D. M., Paper read at B.M.A. Conference. January 1968. Published by Central Council for Health Education.

\section{Streamlined Athlete}

The effect of winds on walking or running is familiar to all of us. It can be specially important to people who are old, or enfeebled, or exhausted in rough country. But quantitative assessment of the effect is far from easy. L. G. C. E. Pugh ${ }^{1}$ has now described the results of measurements made on persons running and walking on a treadmill against winds of various speeds, and has compared these with the effects of going uphill at different elevations of the treadmill.

The aerodynamic problems present some difficulty, as do the experimental aspects of the subject. But the results are of some practical importance to athletes. Pugh has shown that a considerable advantage is to be gained by an athlete running in the shadow of a competitor. As he points out, "The effect of shielding is of course well known to athletes and team managers, but they have regarded it as a subjective effect. The observation that it has a physiological basis may enable them to use it with greater tactical understanding than before." His results are also of interest to hill walkers. Their oxygen consumption can increase from 0.77 to $2.11 . / \mathrm{min}$ when walking at a speed of $1.25 \mathrm{~m} / \mathrm{sec}$ $(2.8 \mathrm{mph})$ when the wind increases from calm conditions to a gale at $18.5 \mathrm{~m} / \mathrm{sec}(40 \mathrm{mph})$. Such a rise in oxygen consumption can easily lead to exhaustion in a short time, and explains the relative frequency of collapse and hypothermia if the weather is cold and wet as well as windy. Patients suffering from angina commonly complain that they suffer pain and distress walking against the wind a distance they can comfortably accomplish on a calm day. The results reported by Pugh indicate that this can be explained on the basis of the increased energy expenditure required.

The effects of air resistance and air movement were studied by A. V. Hill" in a paper on "The Air-resistance to a Runner." He developed an equation based on experiments with a model in a wind tunnel, but the mechanical efficiency of the runner or walker in combating the pressure of the wind could not be calculated from such experiments. Pugh $^{3}$ calculated the energy required to run against the wind by measuring the oxygen consumption of trained athletes on a treadmill in a wind tunnel. The intake of oxygen measured on one athlete running at constant speed but at different wind velocities increased as the wind increased, and the extra intake was related to the square of the wind speed. From his results it appeared that in middle distance running $(5,000$ to $10,000 \mathrm{~m})$ about $8 \%$ of the energy spent running on the track was in overcoming air resistance.

In a further series of measurements Pugh $^{1}$ tried to estimate the mechanical efficiency of work against wind. The cal- culation was based on the measured difference of oxygen consumption running in still air and against wind, together with measurements of the surface area of the person's body and the pressure exerted by the wind against it. $\mathrm{Hill}^{2}$ and R. Margaria ${ }^{4}$ had expressed the air pressure in terms of an equivalent gradient, as though the runner were going uphill. Margaria considered that the mechanical efficiency of lifting work-that is, of lifting the body up a hill-was about $25 \%$ and that the mechanical efficiency of work to overcome air resistance would be the same. B. B. Lloyd ${ }^{5}$ examined world records on different running events and calculated the various limiting factors, using the figure of $25 \%$ for mechanical efficiency related to air resistance. However, he found a more satisfactory agreement between calculated and observed results if he used a figure of $50 \%$. Pugh's results now show that the mechanical efficiency of walking or running against wind is considerably higher than going up a gradient and justify Lloyd's use of $50 \%$ in his equations.

A number of questions remain to be answered, particularly why there should be this difference between wind and gradient. Athletes and their coaches may have to study the niceties of aerodynamics. As Pugh points out, at the highest running speeds variations in the shape of trunk and limbs (and of clothing) can affect resistance. We may perhaps look forward to the streamlined athlete.

\footnotetext{
1 Pugh, L. G. C. E., fournal of Physiology, 1971, 213, 255.

Hill, A. V., Proceedings of the Royal Society, Series B, 1928, 102, 380.

Pugh, L. G. C. E., Fournal of Physiology, 1970, 207, 823.

Margaria, R., Internationale Zeitschrift für angewandte Physiologie einschliesslich Arbeitsphysiologie, 1968, 25, 352.

Lloyd, B. B., Circulation Research, 1967, 20 and 21, suppl. No. 1, p. 218.
}

\section{Blue Valve Syndrome}

One of the less well known disorders of the heart valves is mucoid degeneration, a condition in which the leaflets are thin and diaphanous and have a blue colour owing to a replacement of their substance by mucoid material. This mucoid change may also affect the annulus of the valve and the chordae tendineae, but there is no fibrosis, and the chordae are delicate and of normal length. Histologically there is no accompanying inflammation or fibrosis, and the mucoid material gives the histochemical stains of an acid mucopolysaccharide.

The weakening of the valve structure consequent on its loss of substance causes the leaflets to prolapse in the associated chamber of the heart, and this leads to severe, progressive incompetence without stenosis. R. C. Read and his colleagues reported nine cases in 1965, and they called the condition the floppy valve syndrome. ${ }^{1}$ The mitral valve is most often affected, and rheumatic valvulitis is closely mimicked. When the aortic valve is affected alone, syphilitic disease must be ruled out by serological tests. Occasionally there is a combined mitral and aortic lesion, and in one case the mitral and tricuspid valves were affected. ${ }^{2}$ The sexes are affected aboul equally, and most cases have been reported in young and middle-aged adults. The condition proceeds to intractable heart failure.

In some cases the valve has been replaced with a prosthesis. While the immediate result is often satisfactory, there is a tendency for the prosthesis to break loose from the annulus at a later date. P. L. Wolf and R. C. Read encountered this 
dehiscence of the prosthesis only in cases of mucoid degeneration. ${ }^{3}$ Recently another case has been described by L. J. McCarthy and P. L. Wolf in a man aged $70^{4}$ who had had a murmur for at least 20 years previously. He was admitted in heart failure with severe mitral incompetence, and a valvular replacement was performed. He died four days later with a cerebral infarct. The excised mitral valve contained pools of blue mucoid material.

Mucoid degeneration of the heart valves has long been recognized as an association of Marfan's syndrome, ${ }^{15}$ but it is much less common than Erdheim's cystic medionecrosis of the aorta, which predisposes to dissecting aneurysm. In some of the cases of isolated mucoid degeneration there have been stigmata of Martin's sydrome, ${ }^{15}$ notably some skeletal manifestations. These presumably represent a forme fruste of the syndrome. In many others, including that of McCarthy and Wolf, there were no such stigmata, and the lesion appears to be a localized disorder of the valvular connective tissue.

This condition is not as uncommon as would appear from its infrequent description. In one series of 140 patients who had had one or more valves excised between the years 1961 and 1967 there were 21 cases of mucoid degeneration. ${ }^{6}$ It is also a predisposing factor to infective endocarditis. ${ }^{1}$ These considerations and the troubles that may follow valvular replacement make mucoid degeneration a lesion to be watched for by surgeon and pathologist.

' Read, R. C., Thal, A. P., and Wendt, V. E., Circulation, 1965, $32,897$. 2 Castleman, B., and McNeely, B. U., New England fournal of Medicine, $1967,277,92$.

3 Wolf, P. L., and Read, R. C., American fournal of Clinical Pathology, $1964,42,518$.

- McCarthy, L. J., and Wolf, P. L., American fournal of Clinical Pathology, 1970, 54, 852.

s McKusick, V. A., Heritable Disorders of Connective Tissue, 3rd edn, p. 85. St. Louis, Mosby, 1966

- Frable, W. J., American fournal of Clinical Pathology, 1969, 52, 84.

\section{Ocular Bobbing}

In the Brave New Medical World of double-blind trials and parameters we are apt to look back wistfully to those halcyon days when simple clinical observation was all that mattered, when the wiseacre at the bedside could notice something out of the ordinary, and then immortalize his finding (and often his name) for posterity. And around the eyes, which are so often the signpost to the body's ills, a host of signs and syndromes (with unforgettable or all too easily forgettable eponyms) have accumulated over the last decades. So the recent description of "ocular bobbing" is an echo of this hallowed tradition.

Ocular bobbing is a distinctive, spontaneous eye movement having an abrupt, spontaneous downward jerk of the eyes and a slow return to the mid-position. It is readily distinguishable from the down-beating nystagmus (with the opposite slow-fast sequence) and the pendular movements of an ocular myoclonus. C. M. Fisher ${ }^{1}$ first described it ten years ago in patients with paralysis of horizontal conjugate eye movements. Four subsequent observers have added to the literature, which now musters 25 cases. The latest report, by $J$. $O$. Susac and colleagues ${ }^{2}$ subdivides bobbing into the "typical" form, "monocular" form (having a coexisting ocular palsy), and an "atypical" form, and will doubtless help to establish the condition as a clinical entity for the textbooks and examinations of the future.
The importance of this curious anomaly remains uncertain. It is usually noted in patients who are moribund (from intrapontine haemorrhage or similarly grave disorders) if not actually in their terminal coma, and its mechanism is obscure. But further cases will surely be reported, and so we may learn more about it. Any reminder of the value of plain clinical observation must always be welcome.

1 Fisher, C. M., in Pathogenesis and Treatment of Cerebrovascular Disease. A symposium edited by W. S. Fields. Illinois, Thomas, 1961 . Susac, J. O., Hoyt, W. F., Daroff, R. B., and Lawrence, W., foumal of Neurology, Neurosurgery and Psychiatry, 1970, 33, 771.'

\section{Dermatitis Herpetiformis}

Job "took a potsherd to scrape himself withal." Though we may suspect, in view of his many troubles, that he was suffering from disseminated neurodermatitis with severe secondary infection, dermatitis herpetiformis has been suggested as a possible diagnosis. This too may have been the disease that caused Marat to spend so much of his time in the bath where Charlotte Corday stabbed him.

Dermatitis herpetiformis is a comparatively uncommon skin disease, but it deserves attention because of its favourable response to certain drugs and because the mucosa of the small intestine is often atrophic. Itch is the predominant symptom. It can reach an unbearable intensity, destroy sleep, embarrass its victim by making him scratch in public, and render him miserable and demoralized. The eruption appears in symmetrical patches-for example, over the shoulders, buttocks, elbows, and thighs. Within each patch are commonly a variety of lesions-weals, papules, vesicles, or bullae, scratch marks (often complicated by secondary pyogenic infection), pigmentation, and the scars of healed lesions. It is unusual to find a patient with dermatitis herpetiformis in whom vesicles or bullae do not appear at some time during the course of his disease. In children the blisters can be large and grouped round the mouth and genital region.

A common error in diagnosis is scabies. Other infestations must also be excluded, and onchocerciasis is a possibility in patients who have lived in those parts of the tropics where it is endemic.

Dapsone or sulphapyridine by mouth will suppress the lesions within a week, but they will recur when the dose falls below an optimal level that must be determined for each patient. Satisfactory control depends on carefully supervised treatment. The suppressive dose usually falls gradually over a course of years, and it may be possible to stop treatment altogether eventually. Though inorganic arsenic-for example, Fowler's solution-also clears the lesions, it is unsafe to give because of the risk of long-delayed serious effects such as cirrhosis of the liver and carcinoma. If the patient does not respond to treatment, the diagnosis should be reviewed with special reference to chronic liver or kidney disease, reticulosis, occult carcinoma, or disseminated neurodermatitis.

The aetiology of the disease remains obscure. The suppressive action of sulphapyridine does not depend on its antibacterial activity. The eruption will reappear promptly after years of suppression if the treatment is stopped, and it is interesting that under these circumstances the blisters may be unusually large. These drugs may block some metabolic pathway on which the eruption of lesions depends. The discovery that enteropathy can accompany dermatitis herpeti- 